\title{
Systemic immune-inflammation index as a prognostic marker in patients with newly diagnosed metastatic nasopharyngeal carcinoma: a propensity score-matched study
}

\author{
Cheng Lin", Sheng Lin", Qiao-Juan Guo, Jing-Feng Zong, Tian-Zhu Lu, Na Lin, Shao-Jun Lin, \\ Jian-Ji Pan \\ Department of Radiation Oncology, Fujian Cancer Hospital \& Fujian Medical University Cancer Hospital, Fuzhou 350000, China \\ Contributions: (I) Conception and design: JJ Pan, C Lin; (II) Administrative support: SJ Lin; (III) Provision of study materials or patients: JF Zong, \\ QJ Guo; (IV) Collection and assembly of data: C Lin, S Lin, TZ Lu, N Lin; (V) Data analysis and interpretation: C Lin, S Lin; (VI) Manuscript \\ writing: All authors; (VII) Final approval of manuscript: All authors. \\ \#These authors contributed equally to this work. \\ Correspondence to: Jian-Ji Pan. Department of Radiation Oncology, Fujian Cancer Hospital \& Fujian Medical University Cancer Hospital, Fuzhou \\ 350014, China. Email: panjianji1956@163.com.
}

\begin{abstract}
Background: Systemic immune-inflammation index (SII) is significantly associated with poor survival in variety of cancers. However, SII has not yet been investigated in patients with newly diagnosed metastatic nasopharyngeal carcinoma (mNPC). Thus, our aim is to explore the role of SII in metastatic Nasopharyngeal Carcinoma.

Methods: Two hundred and forty-three patients with newly diagnosed mNPC were retrospectively enrolled. The Kaplan-Meier analysis and Cox regression analysis was performed to evaluate the prognostic value of SII in overall survival (OS) and progression-free survival (PFS). Heterogeneity of factors was balanced by using propensity score-matched (PSM) analysis (1:1 for high SII versus low SII).

Results: Kaplan-Meier analysis showed that patients with high SII were associated with poor median OS (18.0 vs. $36.0 \mathrm{~m}, \mathrm{P}<0.001)$ and PFS (10.0 vs. $22.0 \mathrm{~m}, \mathrm{P}<0.001)$ in $\mathrm{mNPC}$. The Cox regression analysis suggested that high SII was a prognostic factor for OS (HR 1.75, 95\% CI: 1.22-2.52, P=0.001) and PFS (HR 1.69, 95\% CI: 1.22-2.35, P=0.002). PSM analysis still confirmed that SII was an independent marker for OS (HR 1.86, 95\% CI: 1.22-2.83, P=0.004) and PFS (HR 1.84, 95\% CI: 1.23-2.77, P=0.003).

Conclusions: SII is an independent prognostic biomarker for poor OS and PFS in patients with newly diagnosed $\mathrm{mNPC}$ and might be a promising tool for guiding treatment strategy decisions.
\end{abstract}

Keywords: Nasopharyngeal carcinoma (NPC); systemic immune-inflammation index (SII); biomarker; prognosis

Submitted Apr 24, 2019. Accepted for publication Sep 04, 2019.

doi: $10.21037 /$ tcr.2019.09.25

View this article at: http://dx.doi.org/10.21037/tcr.2019.09.25

\section{Introduction}

Nasopharyngeal carcinoma (NPC) is a common cancer in southern China, with an annual incidence of roughly 15-30 per 100,000 (1). Approximately $6 \%$ of NPC patients develop metastases at the time of diagnosis (2), indicating a poor prognosis. The median OS of metastatic NPC (mNPC) is only 15.5 or 21.4 months when receiving chemotherapy alone or radiotherapy combined with chemotherapy, respectively (3). With the advance of intensity modulated radiotherapy (IMRT), the overall survival prognosis for early or locally advanced NPC has improved significantly. However, patients with mNPC appear to benefit the least from IMRT (4). Therefore, it is of the utmost importance to explore novel prognostic markers, such as serum lactic dehydrogenase, haemoglobin and alkaline phosphatase, to better improve stratification and treatment in patients with 
$\operatorname{mNPC}(5,6)$.

It is now well acknowledged that inflammation play a crucial role in the proliferation and progression of cancer $(7,8)$. And inflammation is thought to be a hallmark of cancer, presenting a tumor-promoting inflammatory microenvironment and a reaction of host immune response $(9,10)$. Of note, systemic inflammation, including small inflammatory proteins, acute-phase proteins, circulating cytokines and circulating immune cells, is a good biomarker of prognosis in cancers (7). Recently, several systemic inflammation markers, like platelet lymphocyte ratio (PLR), neutrophil lymphocyte ratio (NLR), derived NLR (dNLR) and systemic immune-inflammation index (SII) have been found to a novel prognostic marker in a variety of cancers $(11,12)$, including NPC (13-18). However, SII has not been reported in mNPC. Therefore, the aim of this study was to evaluate the prognostic value of SII in newly diagnosed mNPC patients.

\section{Methods}

\section{Patients}

From January 2007 to July 2015, 243 patients with metastatic Nasopharyngeal carcinoma (mNPC) were enrolled in Fujian Cancer Hospital, China. Inclusion criteria included: (I) patients were newly and histologically diagnosed with mNPC; (II) patients should receive radiotherapy or at least one cycle of chemotherapy. Exclusion criteria included: (I) patients with NPC developed metastasis after first-line therapy; (II) patients with other types of cancer; (III) patients refuse any antitumor treatment all the way, including radiotherapy, chemotherapy or best support care; (IV) patients who were lost in the follow up.

All patients received a complete pre-treatment evaluation, including medical history and physical examination, nasopharyngeal fiberoptic endoscopy examination, standard hematology and blood biochemistry tests, magnetic resonance imaging (MRI) or computed tomography (CT) scan of the head and neck, chest $\mathrm{X}$-ray photography, ultrasound examination of the liver and abdomen and whole-body bone scan. Thoracic and abdominal CT scans, MRI of the bone or liver and positron emission tomography/computed tomography (PET/CT) were applied when clinically indicated. This study was approved by the Ethical Review Committee of Fujian Cancer Hospital (No. SQ2019-031-01). All of the participants signed an informed consent form.

Peripheral blood was administrated and tested for SII before radiotherapy. The SII was defined as follows: $\mathrm{SII}=\mathrm{P} \times \mathrm{N} / \mathrm{L}$, where $\mathrm{P}, \mathrm{N}$ and $\mathrm{L}$ was the absolute preoperatively peripheral platelet, neutrophil and lymphocyte counts, respectively (19).

\section{Clinical data and treatment}

Among 243 patients, 55 (22.6\%) patients suffered from multiple organ metastases. One hundred and five and 112 patients received two-dimensional radiotherapy (2DRT) or IMRT of the primary tumor, respectively. The planning and delivery of 2DRT and IMRT were applied as previous study $(20,21)$. The median dose was $69.75 \mathrm{~Gy}$ (range, $6-79.55 \mathrm{~Gy}$ ) in the above 217 patients. $100 \%$ patients received at least one induction chemotherapy. The regimen of induction chemotherapy was platinum-based two or three drugs combination chemotherapy. Eighty-four (34.6\%) patients received concurrent chemoradiotherapy, and $100(41.2 \%)$ patients received concurrent chemotherapy. As to the metastatic foci, 64 patients with bone metastasis and 3 patients with distant lymph nodes were treated with local radiotherapy. Percutaneous alcohol injection therapy was applied to 4 patients with localized liver metastatic lesions. 8 patients underwent radiotherapy or resection of metastatic lung lesions.

\section{Follow-up}

Patients were evaluated every 3 months for the first 2 years, every 6 months from year 3-5, and then every 12 months. The overall survival (OS) was measured from the date of diagnosis to the date of death or the last follow up. The progression-free survival (PFS) was measured from the date of diagnosis to the time of document treatment failure or last follow up. The last follow up time was June, 2018. The median follow-up period was 77 months (range, 2.0-135.0).

\section{Statistical analysis}

Data analysis was performed using SPSS version 22 software (SPSS Inc., Chicago, IL, USA). The relationship between SII and clinicopathologic characteristics was analyzed using $\chi^{2}$ test or Fisher's exact test. Kaplan-Meier survival method and log-rank test were used to compare the survival rates between different groups. Univariate and multivariate 
Table 1 Baseline patient characteristics and correlation between systemic immune-inflammation index and clinical variables

\begin{tabular}{|c|c|c|c|c|c|c|c|}
\hline Variables & Total (\%) & \multicolumn{3}{|c|}{ Unmatched data } & \multicolumn{3}{|c|}{ PSM matched data } \\
\hline Sex & & & & 0.686 & & & 1.000 \\
\hline Female & 39 (24.3) & 29 & 10 & & 47 & 47 & \\
\hline Male & $184(75.7)$ & 157 & 47 & & 10 & 10 & \\
\hline$\leq 50$ & $134(55.1)$ & 97 & 37 & & 37 & 37 & \\
\hline$>50$ & 109 (44.9) & 89 & 20 & & 20 & 20 & \\
\hline T category & & & & 0.499 & & & 0.706 \\
\hline $\mathrm{T} 1$ & $30(12.3)$ & 24 & 6 & & 7 & 6 & \\
\hline $\mathrm{T} 4$ & $71(29.2)$ & 52 & 19 & & 22 & 19 & \\
\hline $\mathrm{N}$ category & & & & 0.047 & & & 0.906 \\
\hline No & $2(0.8)$ & 2 & 0 & & 0 & 0 & \\
\hline $\mathrm{N} 1$ & $33(13.6)$ & 29 & 4 & & 5 & 4 & \\
\hline N2 & 92 (37.9) & 75 & 17 & & 18 & 17 & \\
\hline N3 & $116(47.7)$ & 80 & 36 & & 34 & 36 & \\
\hline Histology & & & & 0.498 & & & 0.549 \\
\hline I & $4(1.6)$ & 3 & 1 & & 0 & 1 & \\
\hline IMRT & & & & 0.002 & & & 0.321 \\
\hline No & $131(53.9)$ & 90 & 41 & & 35 & 41 & \\
\hline Yes & $112(46.1)$ & 96 & 16 & & 22 & 16 & \\
\hline
\end{tabular}

ECOG, Eastern Cooperative Oncology Group performance; IMRT, intensity modulated radiotherapy; SIl, systemic immune-inflammation index; I, Keratinizing squamous cell carcinoma; II, non-keratinizing differentiated carcinoma; III, non-keratinizing undifferentiated carcinoma.

analyses were calculated using the Cox proportional hazards model. variables with statistical significance $(\mathrm{P}<0.05)$ in Univariate analyses were further included in multivariate analyses. Survival tree analysis was performed and recursivepartitioning analysis (RPA) was used to identify the optimal cutoff thresholds of SII as we previous described (22). A P value of less than 0.05 was considered statistically significant.

\section{Results}

\section{Characteristics of patients}

The characteristics of $\mathrm{mNPC}$ are shown in (Table 1). The staging of mNPC was classified according to the American Joint Committee on Cancer (AJCC) and the Union for International Cancer Control (UICC), 8th Edition. Of 
Table 2 Univariate and multivariate analysis of overall survival in patients with metastatic nasopharyngeal carcinoma patients (unmatched data)

\begin{tabular}{|c|c|c|c|c|}
\hline \multirow{2}{*}{ Variables } & \multicolumn{2}{|c|}{ Univariate analysis } & \multicolumn{2}{|c|}{ Multivariate analysis } \\
\hline & $\mathrm{HR}(95 \% \mathrm{Cl})$ & $\mathrm{P}$ & HR $(95 \% \mathrm{Cl})$ & $\mathrm{P}$ \\
\hline Sex & & 0.094 & & \\
\hline Female vs. male & $\begin{array}{c}0.70 \\
(0.46-1.06)\end{array}$ & & & \\
\hline
\end{tabular}

\begin{tabular}{|c|c|}
\hline Age, years & \\
\hline$>50$ vs. $\leq 50$ & $\begin{array}{c}1.33 \\
(0.99-1.79)\end{array}$ \\
\hline
\end{tabular}

0.056

T classification

$\begin{array}{ccc}\text { T1 } & 1 & \\ \text { T2 } & 0.89 & 0.666 \\ & (0.51-1.54) & \\ \text { T3 } & 1.14 & 0.616 \\ & (0.69-1.87) & \\ \text { T4 } & 1.11 & 0.695 \\ & (0.66-1.85) & \\ \text { N classification } & & 0.017 \\ \text { N0 } & 1 & \\ \text { N1 } & 0.86 & 0.881 \\ & (0.12-6.41) & \\ \text { N2 } & 1.16 & 0.886 \\ & (0.52-1.22) & \\ \text { N3 } & 1.69 & 0.602 \\ & (0.24-12.15) & \end{array}$

Histology$$
\text { I }
$$$$
\text { II }
$$

III

ECOG

1 vs. 0

IMRT

Yes vs. no

SII

$\geq 930$ vs. $<930$
1

$$
0.52
$$$$
\text { (0.25-1.01) }
$$

0.67 (0.17-2.69)

$$
1.41
$$$$
\text { (0.95-2.10) }
$$

$$
\begin{aligned}
& 0.053 \\
& 0.567 \\
& 0.08
\end{aligned}
$$

$<0.001$

$$
0.49
$$$$
\text { (0.36-0.66) }
$$

$$
<0.001
$$

$<0.001$

$$
0.53
$$$$
(0.39-0.73)
$$

$<0.001$

0.001

$$
2.04
$$$$
\text { (1.47-2.82) }
$$

$$
<0.001
$$

all 243 patients, the median age was 48 years (range, $17-81$ years), and the proportion of male (75.7\%) were three times that of female (39\%). Non-keratinizing undifferentiated carcinoma accounts for more than $90 \%$ of all NPC. At last follow up, 178 (73.3\%) patients had died. The median OS and PFS for all patients was 31.5 (range, 2-135) months and 19.0 (range, 1-135) months, respectively. The estimated OS for 1-, 3- and 5-year was $79.8 \%, 43.5 \%$ and $31.5 \%$, respectively.

\section{Association between SII and characteristics in mNPC}

Optimal cutoff thresholds of SII is determined by High SII (>930) was present in 57 (23.46\%) mNPC patients (Table 1). High SII was associated with advanced $\mathrm{N}$ stage $(\mathrm{P}=0.047)$ and patients without IMRT therapy $(\mathrm{P}=0.002)$. No statistically significant difference was observed between SII level and gender, age at diagnosis, $\mathrm{T}$ classification, pathological type and ECOG score (Table 2).

\section{The prognostic significance of SII in patients with mNPC}

The Kaplan-Meier analysis indicated that high SII were closely associated with poor median OS (18.0 vs. $36.0 \mathrm{~m}$, $\mathrm{P}<0.001)$ and PFS (10.0 vs. $22.0 \mathrm{~m}, \mathrm{P}<0.001)$ (Figure 1).

As shown in Table 2 and Table 3, Univariate analysis indicated that SII were significantly associated with worse median OS (HR 2.04, 95\% CI: 1.47-2.82, $\mathrm{P}<0.001$ ) and PFS (HR 1.84, 95\% CI: 1.34-2.54, $\mathrm{P}<0.001$ ). Multivariate analysis further identified that SII was an independent prognostic factors for OS (HR 1.75, 95\% CI: 1.22-2.52, $\mathrm{P}=0.001)$ and PFS (HR 1.69, 95\% CI: 1.22-2.35, $\mathrm{P}=0.002$ ), as well as IMRT.

\section{Propensity score matching (PSM) analysis}

In order to eradicate the imbalance of $\mathrm{N}$ category and IMRT between SII $\leq 930$ and SII >930, we performed PSM analysis. One hundred and fourteen $\mathrm{mNPC}$ were enrolled and all variables were distributed equally in both group $(\mathrm{P}>0.3)$. Kaplan-Meier analysis indicated that low SII were significantly associated with prolonged median OS $(\mathrm{P}=0.001)$ and PFS ( $\mathrm{P}=0.002)$ (Figure 2).

Univariate analysis suggested SII were associated with OS and PFS (Tables 4,5). Multivariable analyses still demonstrated that SII were independent prognostic factors for OS (HR 1.86, 95\% CI: 1.22-2.83, P=0.004) and PFS (HR 1.84, 95\% CI: 1.23-2.77, $\mathrm{P}=0.003$ ). 

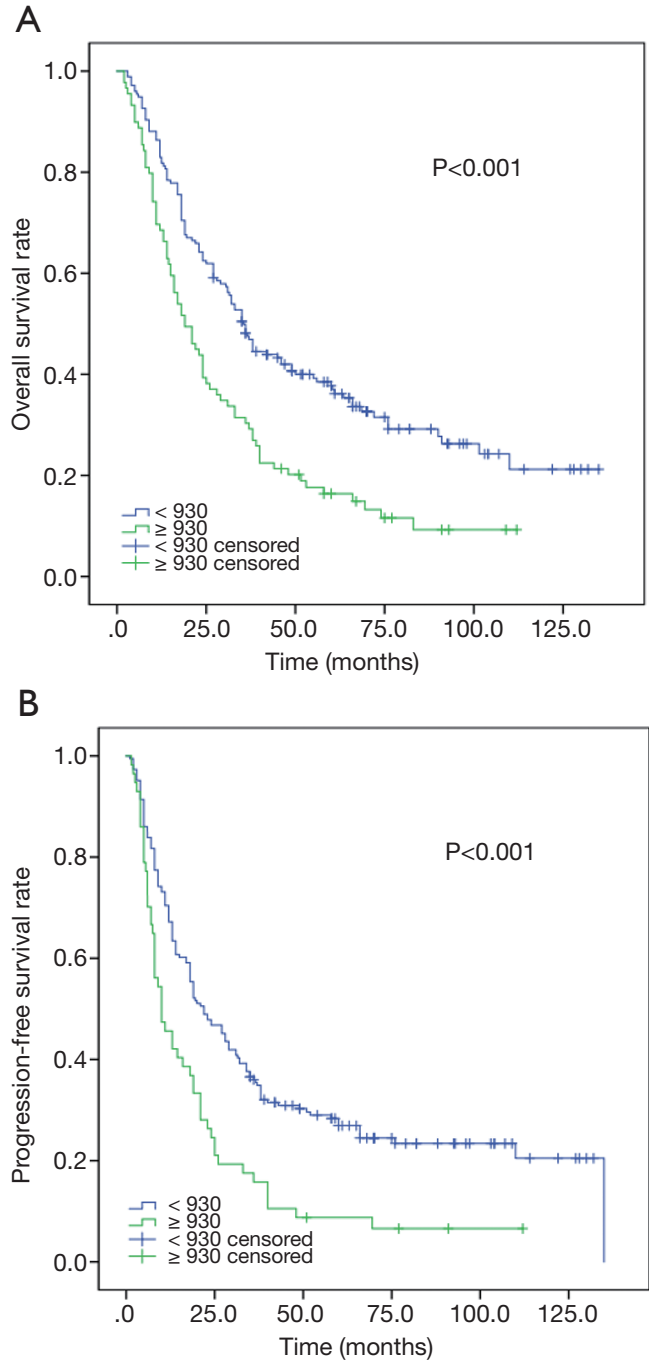

Figure 1 Kaplan-Meier analysis for OS and PFS according to SII in 243 patients with metastatic Nasopharyngeal carcinoma. (A) Kaplan-Meier analysis for OS. (B) Kaplan-Meier analysis for PFS.

\section{Discussion}

It is now well established that inflammation can increase cancer risk by causing oncogenic mutations, genomic instability, tumor promotion, angiogenesis and metastasis, and can lead to an immunosuppressive microenvironment $(9,10)$. During the inflammatory process, different subtypes of inflammatory and immune cells were released and involved in tumor-promoting inflammation and anti-tumor immunity. Therefore, it is meaningful to explore a tool that can simply and accurately predict the state of inflammation according to these inflammatory and immune cells in cancers.
Table 3 Univariate and multivariate analysis of progression-free survival in patients with metastatic nasopharyngeal carcinoma patients (unmatched data)

\begin{tabular}{lccccc}
\hline \multirow{2}{*}{ Variables } & \multicolumn{2}{c}{ Univariate analysis } & & \multicolumn{2}{c}{ Multivariate analysis } \\
\cline { 2 - 3 } Sex & $\mathrm{HR}(95 \% \mathrm{Cl})$ & $\mathrm{P}$ & & $\mathrm{HR}(95 \% \mathrm{Cl})$ & $\mathrm{P}$ \\
\hline Female vs. male & 0.81 & 0.286 & & \\
& & & & \\
& $(0.54-1.20)$ & &
\end{tabular}

Age, years

0.112

$>50$ vs. $\leq 50$

1.26 $(0.95-1.67)$

T classification

T1

T2

1

1.00

0.994

$(0.58-1.71)$

T3

1.33

(0.81-2.18)

T4

1.20

0.472

(0.73-2.00)

$\mathrm{N}$ classification

NO

1

N1

1.21

0.852

(0.16-9.01)

N2

1.58

0.649

$(0.22-11.39)$

N3

2.47

(0.34-17.72)

0.369

I

II

0.55

(0.29-1.05)

III

0.79

$(0.255-2.48)$

ECOG

1 vs. 0

1.19

(0.80-1.77)

IMRT

0.004

0.034

Yes vs. no

0.66

(0.49-0.88)

0.73

(0.54-0.98)

SII

$<0.001$

0.002
1.84

(1.34-2.54)
1.69

(1.22-2.35)

ECOG, Eastern Cooperative Oncology Group performance; IMRT, intensity modulated radiotherapy; HR, hazard ratio; Cl, confidence interval. SII, systemic immune-inflammation index. 


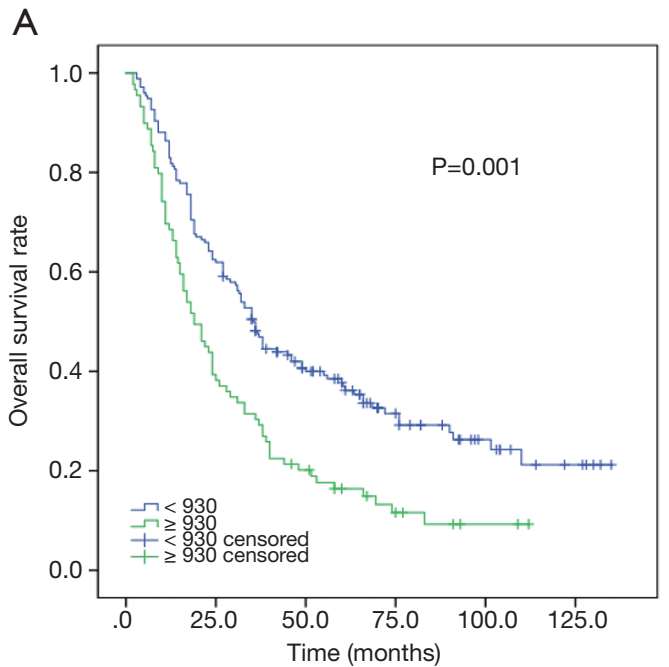

B

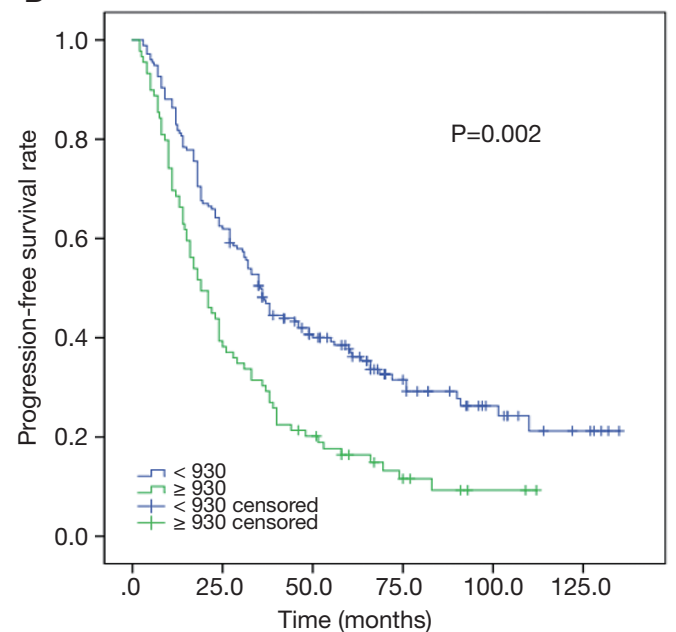

Figure 2 Kaplan-Meier analysis for OS and PFS according to SII in 114 patients with metastatic Nasopharyngeal carcinoma (Propensity score matched analysis). (A) Kaplan-Meier analysis for OS. (B) Kaplan-Meier analysis for PFS.

Recently, SII, based on 3 immune inflammatory cells (lymphocyte, neutrophil and platelet) from peripheral blood, was considered to be a promising inflammatory marker. Accumulated data have proved that SII was a novel prognostic indicator in various cancers, including non-small cell lung cancer (23-26), hepatocellular Carcinoma (19,27,28), esophageal cancer (29-32), colorectal cancer (33), gastric cancer (34-36), renal cell cancer (37), prostate cancer (38) and pancreatic cancer (39). However, SII has not been thoroughly studied in NPC. Previous studies have focused on prognostic significance of NLR $\backslash P L R$ and percentages of neutrophil and lymphocyte in NPC $(16,18,40)$. In addition, the roles of SII were just reported in two studies in NPC and no detailed examination in MNPC patients $(13,41)$. It is worth noting that mNPC were more in need of prognostic biomarkers, as those patients have a median OS of only 12-15 months with platinum-based chemotherapy (42).

Our study underscores the potential of SII in mNPC, suggesting that SII was a prognostic biomarker for poor OS and PFS. This view was basically consistent with previous studies, which found that SII was unfavorable indicator for OS in all stages of NPC $(14,41)$. While, our report found no significant relationships between SII and clinical characteristics. The discrepancies are likely due to the registration of different populations, which might lead to the different cutoff value of SII and various outcomes. More work remains to determine the different roles of inflammatory markers involved between non-metastatic $\mathrm{NPC}$ and mNPC.

The mechanisms why high SII results in adverse outcome may be explained by the following reasons. Firstly, patients with higher SII often have thrombocytosis, which is commonly observed in metastatic cancers (43). Platelets can significantly promote cancer in variety of ways, such as inducing angiogenesis, resisting cell death, sustaining proliferative signals, supporting cancer stem cell and evading immune detection (44). In addition, study have showed that platelets could induce the production of circulating cancer cells (CTCs) and protect CTCs from immune attacks. And platelets-derived TGF- $\beta$ and PDGF could induce epithelial-mesenchymal transition (EMT) in CTCs and help them intravasation and extravasation (45). Secondly, neutrophils, as the first line of innate immune system, were proved to promote metastasis through neutrophil extracellular traps (NET). NET could wrap up CTCs and cause micrometastases spread safely to the metastatic sites (46). Consistent with platelets, subpopulations of tumor-associated neutrophils could aid tumorigenesis through plenty of ways, like promoting tumor proliferation, angiogenesis and genetic instability. More importantly, tumor-associated neutrophils will suppress $\mathrm{CD}^{+} \mathrm{T}$ cell, leading to immune invasion (47). Currently, there is growing evidence that neutrophils could facilitate metastasis by creating a systemic immunosuppressive microenvironment and a "pre-metastatic niche" within metastatic organs $(48,49)$. And neutrophils were reported to be closely associated with poor prognosis of different cancers treated with radiation therapy (50). Finally, NPC is characterized by massive infiltration of lymphocytes (51). 
Table 4 Univariate and multivariate analysis of overall survival in patients with metastatic nasopharyngeal carcinoma patients (PSM matched data)

\begin{tabular}{|c|c|c|c|c|}
\hline \multirow{2}{*}{ Variables } & \multicolumn{2}{|c|}{ Univariate analysis } & \multicolumn{2}{|c|}{ Multivariate analysis } \\
\hline & $\mathrm{HR}(95 \% \mathrm{Cl})$ & $P$ & $\mathrm{HR}(95 \% \mathrm{Cl})$ & $P$ \\
\hline Sex & & 0.057 & & \\
\hline Female vs. male & $\begin{array}{c}0.56 \\
(0.31-1.02)\end{array}$ & & & \\
\hline
\end{tabular}

$\begin{array}{lcc}\text { Age, years } & & 0.35 \\ >50 \text { vs. } \leq 50 & 1.23 & \\ & (0.80-1.89) & \\ \text { T classification } & & \\ \text { T1 } & 1 & \\ \text { T2 } & 0.96 & 0.924 \\ & (0.44-2.11) & \\ \text { T3 } & 0.86 & 0.672 \\ & (0.69-1.87) & \\ \text { T4 } & 0.69 & 0.315 \\ & (0.66-1.85) & \end{array}$

$\mathrm{N}$ classification

$\begin{array}{ccc}\text { N1 } & 1 & \\ \text { N2 } & 1.19 & 0.704 \\ & (0.49-2.89) & \\ \text { N3 } & 1.79 & 0.177 \\ & (0.77-4.16) & \end{array}$

Histology

\begin{tabular}{|c|c|c|c|c|}
\hline I & 1 & & & \\
\hline II & $\begin{array}{c}0.49 \\
(0.25-1.01)\end{array}$ & 0.231 & & \\
\hline III & $\begin{array}{c}4.80 \\
(0.65-35.73)\end{array}$ & 0.125 & & \\
\hline ECOG & & 0.93 & & \\
\hline 1 vs. 0 & $\begin{array}{c}0.98 \\
(0.57-1.68)\end{array}$ & & & \\
\hline IMRT & & 0.013 & & 0.032 \\
\hline Yes vs. no & $\begin{array}{c}0.55 \\
(0.35-0.88)\end{array}$ & & $\begin{array}{c}0.60 \\
(0.37-0.96)\end{array}$ & \\
\hline SII & & 0.002 & & 0.004 \\
\hline$\geq 930$ vs. $<930$ & $\begin{array}{c}1.96 \\
(1.29-2.94)\end{array}$ & & $\begin{array}{c}1.86 \\
(1.22-2.83)\end{array}$ & \\
\hline
\end{tabular}

ECOG, Eastern Cooperative Oncology Group performance; IMRT, intensity modulated radiotherapy; HR, hazard ratio; $\mathrm{Cl}$, confidence interval. SII, systemic immune-inflammation index.
Table 5 Univariate and multivariate analysis of progression-free survival in patients with metastatic nasopharyngeal carcinoma patients (PSM matched data)

\begin{tabular}{|c|c|c|c|c|}
\hline \multirow{2}{*}{ Variables } & \multicolumn{2}{|c|}{ Univariate analysis } & \multicolumn{2}{|c|}{ Multivariate analysis } \\
\hline & $\mathrm{HR}(95 \% \mathrm{Cl})$ & $P$ & $\mathrm{HR}(95 \% \mathrm{Cl})$ & $\mathrm{P}$ \\
\hline Sex & & 0.056 & & \\
\hline Female vs. male & $\begin{array}{c}0.57 \\
(0.33-1.01)\end{array}$ & & & \\
\hline
\end{tabular}

Age, years

0.55

$>50$ vs. $\leq 50$

1.14

(0.75-1.73)

T classification

T1

T2

1

0.87

0.722

(0.40-1.89)

T3

1.03

0.928

(0.51-2.09)

T4

0.78

0.480

(0.38-1.57)

$\mathrm{N}$ classification

0.02

N1

1

N2

1.04

0.938

(0.43-2.51)

N3

$1.89 \quad 0.138$

(0.82-4.39)

Histology

I

II

1

0.88

0.794

(0.32-2.38)

III

$2.06 \quad 0.475$

(0.28-14.97)

ECOG

1 vs. 0

0.89

(0.52-1.52)

IMRT

0.165

Yes vs. no

0.73

(0.47-1.14)

SII

0.003

0.003

$\geq 930$ vs. $<930$

1.84

(1.23-2.77)

1.84

(1.23-2.77)

ECOG, Eastern Cooperative Oncology Group performance; IMRT, intensity modulated radiotherapy; HR, hazard ratio; Cl, confidence interval. SII, systemic immune-inflammation index. 
Tumor infiltrating lymphocytes (TILs) in NPC were common significantly associated with better survival, which was supposed to be an independent and potential prognostic biomarker (52). And several data have also showed that higher peripheral blood lymphocytes predicted a favorable outcome in NPC and other head and neck caner $(18,45,53,54)$.

Although SII proved to be a useful tool for OS and PFS in mNPC. This research has a few limitations. Firstly, it is a retrospective study. Secondly, large heterogeneity of outcomes was noted in mNPC, since there is now no standard therapy for mNPC. Lastly, our study was in a single center and performed in popular areas of NPC. Therefore, more investigation is needed to fully define the validity and practicability of SII. The application of SII in clinical practice should be validated in large sample and randomized studies.

To our knowledge, our study is the first report to examine the role of SII in patients with newly diagnosed mNPC. Our results showed that the SII was a simple and novel tool that could serve as an independent prognostic biomarker for OS and PFS in MNPC patients. Larger model validations and deeper mechanisms underlying the associations between high SII and worse outcomes are truly warranted.

\section{Acknowledgments}

Funding: This study was supported by the Funds of the National Science Foundation of China (grant no. U1405221). Medical Innovation Project of Fujian Province (grant number 2015-CX-6).

\section{Footnote}

Conflicts of Interest: All authors have completed the ICMJE uniform disclosure form (available at http://dx.doi. org/10.21037/tcr.2019.09.25). The authors have no conflicts of interest to declare.

Ethical Statement: The authors are accountable for all aspects of the work in ensuring that questions related to the accuracy or integrity of any part of the work are appropriately investigated and resolved. This study was conducted in accordance with the Declaration of Helsinki (as revised in 2013). This study was approved by the Ethical Review Committee of Fujian Cancer Hospital (No. SQ2019-031-01). All of the participants signed an informed consent form.

Open Access Statement: This is an Open Access article distributed in accordance with the Creative Commons Attribution-NonCommercial-NoDerivs 4.0 International License (CC BY-NC-ND 4.0), which permits the noncommercial replication and distribution of the article with the strict proviso that no changes or edits are made and the original work is properly cited (including links to both the formal publication through the relevant DOI and the license). See: https://creativecommons.org/licenses/by-nc-nd/4.0/.

\section{References}

1. Wei WI, Sham JS. Nasopharyngeal carcinoma. Lancet 2005;365:2041-54.

2. Lee AW, Poon YF, Foo W, et al. Retrospective analysis of 5037 patients with nasopharyngeal carcinoma treated during 1976-1985: overall survival and patterns of failure. Int J Radiat Oncol Biol Phys 1992;23:261-70.

3. Rusthoven CG, Lanning RM, Jones BL, et al. Metastatic nasopharyngeal carcinoma: Patterns of care and survival for patients receiving chemotherapy with and without local radiotherapy. Radiother Oncol 2017;124:139-46.

4. Chua ML, Wee JT, Hui EP, et al. Nasopharyngeal carcinoma. Lancet 2016;387:1012-24.

5. Jin Y, Ye X, Shao L, et al. Serum lactic dehydrogenase strongly predicts survival in metastatic nasopharyngeal carcinoma treated with palliative chemotherapy. Eur J Cancer 2013;49:1619-26.

6. Jin Y, Cai XY, Cai YC, et al. To build a prognostic score model containing indispensible tumour markers for metastatic nasopharyngeal carcinoma in an epidemic area. Eur J Cancer 2012;48:882-8.

7. Diakos CI, Charles KA, McMillan DC, et al. Cancerrelated inflammation and treatment effectiveness. Lancet Oncol 2014;15:e493-503.

8. Mantovani A, Allavena P, Sica A, et al. Cancer-related inflammation. Nature 2008;454:436-44.

9. Hanahan D, Weinberg Robert A. Hallmarks of Cancer: The Next Generation. Cell 2011;144:646-74.

10. Grivennikov SI, Greten FR, Karin M. Immunity, inflammation, and cancer. Cell 2010;140:883-99.

11. Proctor MJ, McMillan DC, Morrison DS, et al. A derived neutrophil to lymphocyte ratio predicts survival in patients with cancer. Br J Cancer 2012;107:695-9.

12. Dolan RD, McSorley ST, Park JH, et al. The prognostic value of systemic inflammation in patients undergoing 
surgery for colon cancer: comparison of composite ratios and cumulative scores. Br J Cancer 2018;119:40-51.

13. Jiang Y, Qu S, Pan X, et al. Prognostic value of neutrophilto-lymphocyte ratio and platelet-to-lymphocyte ratio in intensity modulated radiation therapy for nasopharyngeal carcinoma. Oncotarget 2018;9:9992-10004.

14. Jiang W, Chen Y, Huang J, et al. Systemic immuneinflammation index predicts the clinical outcome in patients with nasopharyngeal carcinoma: a propensity score-matched analysis. Oncotarget 2017;8:66075-86.

15. Sun W, Zhang L, Luo M, et al. Pretreatment hematologic markers as prognostic factors in patients with nasopharyngeal carcinoma: Neutrophillymphocyte ratio and platelet-lymphocyte ratio. Head Neck 2016;38:E1332-40.

16. Chua ML, Tan SH, Kusumawidjaja G, et al. Neutrophilto-lymphocyte ratio as a prognostic marker in locally advanced nasopharyngeal carcinoma: A pooled analysis of two randomised controlled trials. Eur J Cancer 2016;67:119-29.

17. Jin Y, Ye X, He C, et al. Pretreatment neutrophil-tolymphocyte ratio as predictor of survival for patients with metastatic nasopharyngeal carcinoma. Head Neck 2015;37:69-75.

18. He JR, Shen GP, Ren ZF, et al. Pretreatment levels of peripheral neutrophils and lymphocytes as independent prognostic factors in patients with nasopharyngeal carcinoma. Head Neck 2012;34:1769-76.

19. Hu B, Yang XR, Xu Y, et al. Systemic immuneinflammation index predicts prognosis of patients after curative resection for hepatocellular carcinoma. Clin Cancer Res 2014;20:6212-22.

20. Pan J, Tang T, Xu L, et al. Prognostic significance of expression of cyclooxygenase-2, vascular endothelial growth factor, and epidermal growth factor receptor in nasopharyngeal carcinoma. Head Neck 2013;35:1238-47.

21. Lin S, Pan J, Han L, et al. Update report of nasopharyngeal carcinoma treated with reduced-volume intensity-modulated radiation therapy and hypothesis of the optimal margin. Radiother Oncol 2014;110:385-9.

22. Guo Q, Lu T, Chen Y, et al. Genetic variations in the PI3K-PTEN-AKT-mTOR pathway are associated with distant metastasis in nasopharyngeal carcinoma patients treated with intensity-modulated radiation therapy. Sci Rep 2016;6:37576.

23. Tomita M, Ayabe T, Maeda R, et al. Systemic Immuneinflammation Index Predicts Survival of Patients After Curative Resection for Non-small Cell Lung Cancer. In
Vivo 2018;32:663-7.

24. Guo D, Zhang J, Jing W, et al. Prognostic value of systemic immune-inflammation index in patients with advanced non-small-cell lung cancer. Future Oncol 2018;14:2643-50.

25. Gao Y, Zhang H, Li Y, et al. Preoperative increased systemic immune-inflammation index predicts poor prognosis in patients with operable non-small cell lung cancer. Clin Chim Acta 2018;484:272-7.

26. Tong YS, Tan J, Zhou XL, et al. Systemic immuneinflammation index predicting chemoradiation resistance and poor outcome in patients with stage III non-small cell lung cancer. J Transl Med 2017;15:221.

27. Wang BL, Tian L, Gao XH, et al. Dynamic change of the systemic immune inflammation index predicts the prognosis of patients with hepatocellular carcinoma after curative resection. Clin Chem Lab Med 2016;54:1963-9.

28. Yang Z, Zhang J, Lu Y, et al. Aspartate aminotransferaselymphocyte ratio index and systemic immuneinflammation index predict overall survival in $\mathrm{HBV}$-related hepatocellular carcinoma patients after transcatheter arterial chemoembolization. Oncotarget 2015;6:43090-8.

29. Zhang H, Shang X, Ren P, et al. The predictive value of a preoperative systemic immune-inflammation index and prognostic nutritional index in patients with esophageal squamous cell carcinoma. J Cell Physiol 2019;234:1794-802.

30. Wang L, Wang C, Wang J, et al. A novel systemic immune-inflammation index predicts survival and quality of life of patients after curative resection for esophageal squamous cell carcinoma. J Cancer Res Clin Oncol 2017;143:2077-86.

31. Feng JF, Chen S, Yang X. Systemic immune-inflammation index (SII) is a useful prognostic indicator for patients with squamous cell carcinoma of the esophagus. Medicine (Baltimore) 2017;96:e5886.

32. Geng Y, Shao Y, Zhu D, et al. Systemic ImmuneInflammation Index Predicts Prognosis of Patients with Esophageal Squamous Cell Carcinoma: A Propensity Score-matched Analysis. Sci Rep 2016;6:39482.

33. Chen JH, Zhai ET, Yuan YJ, et al. Systemic immuneinflammation index for predicting prognosis of colorectal cancer. World J Gastroenterol 2017;23:6261-72.

34. Chen L, Yan Y, Zhu L, et al. Systemic immuneinflammation index as a useful prognostic indicator predicts survival in patients with advanced gastric cancer treated with neoadjuvant chemotherapy. Cancer Manag Res 2017;9:849-67. 
35. Huang L, Liu S, Lei Y, et al. Systemic immuneinflammation index, thymidine phosphorylase and survival of localized gastric cancer patients after curative resection. Oncotarget 2016;7:44185-93.

36. Wang K, Diao F, Ye Z, et al. Prognostic value of systemic immune-inflammation index in patients with gastric cancer. Chin J Cancer 2017;36:75.

37. Lolli C, Basso U, Derosa L, et al. Systemic immuneinflammation index predicts the clinical outcome in patients with metastatic renal cell cancer treated with sunitinib. Oncotarget 2016;7:54564-71.

38. Fan L, Wang R, Chi C, et al. Systemic immuneinflammation index predicts the combined clinical outcome after sequential therapy with abiraterone and docetaxel for metastatic castration-resistant prostate cancer patients. Prostate 2018;78:250-6.

39. Aziz MH, Sideras K, Aziz NA, et al. The SystemicImmune-Inflammation Index Independently Predicts Survival and Recurrence in Resectable Pancreatic Cancer and its Prognostic Value Depends on Bilirubin Levels: A Retrospective Multicenter Cohort Study. Ann Surg 2019;270:139-46.

40. An X, Ding P-R, Wang F-H, et al. Elevated neutrophil to lymphocyte ratio predicts poor prognosis in nasopharyngeal carcinoma. Tumour Biol 2011;32:317-24.

41. Oei RW, Ye L, Kong F, et al. Prognostic value of inflammation-based prognostic index in patients with nasopharyngeal carcinoma: a propensity score matching study. Cancer Manag Res 2018;10:2785-97.

42. Loong HH, Ma BB, Chan AT. Update on the management and therapeutic monitoring of advanced nasopharyngeal cancer. Hematol Oncol Clin North Am 2008;22:1267-78, x.

43. Gay LJ, Felding-Habermann B. Contribution of platelets to tumour metastasis. Nat Rev Cancer 2011;11:123-34.

44. Franco AT, Corken A, Ware J. Platelets at the interface

Cite this article as: Lin C, Lin S, Guo QJ, Zong JF, Lu TZ, Lin N, Lin SJ, Pan JJ. Systemic immune-inflammation index as a prognostic marker in patients with newly diagnosed metastatic nasopharyngeal carcinoma: a propensity score-matched study. Transl Cancer Res 2019;8(5):2089-2098. doi: 10.21037/ tcr.2019.09.25 of thrombosis, inflammation, and cancer. Blood 2015;126:582-8.

45. Lou XL, Sun J, Gong SQ, et al. Interaction between circulating cancer cells and platelets: clinical implication. Chin J Cancer Res 2015;27:450-60.

46. Cools-Lartigue J, Spicer J, McDonald B, et al. Neutrophil extracellular traps sequester circulating tumor cells and promote metastasis. J Clin Invest 2013. [Epub ahead of print].

47. Mantovani A, Cassatella MA, Costantini C, et al. Neutrophils in the activation and regulation of innate and adaptive immunity. Nat Rev Immunol 2011;11:519-31.

48. Rakic A, Beaudry P, Mahoney DJ. The complex interplay between neutrophils and cancer. Cell Tissue Res 2018;371:517-29.

49. Grecian R, Whyte MKB, Walmsley SR. The role of neutrophils in cancer. Br Med Bull 2018;128:5-14.

50. Schernberg A, Blanchard P, Chargari C, et al. Neutrophils, a candidate biomarker and target for radiation therapy? Acta Oncol 2017;56:1522-30.

51. Huang YT, Sheen TS, Chen CL, et al. Profile of cytokine expression in nasopharyngeal carcinomas: a distinct expression of interleukin 1 in tumor and CD4+ T cells. Cancer Res 1999;59:1599-605.

52. Zhang YL, Li J, Mo HY, et al. Different subsets of tumor infiltrating lymphocytes correlate with NPC progression in different ways. Mol Cancer 2010;9:4.

53. Li J, Jiang R, Liu WS, et al. A large cohort study reveals the association of elevated peripheral blood lymphocyte-to-monocyte ratio with favorable prognosis in nasopharyngeal carcinoma. PLoS One 2013;8:e83069.

54. Wu YY, Chang KP, Lin CY, et al. Prognostic significance of combined pretreatment lymphocyte counts and body mass index in patients with head and neck cancer treated with radiation therapy. Cancer Med 2018. [Epub ahead of print]. 